\section{Allotment Gardening and Other Leisure Activities for Stress Reduction and Healthy Aging}

\author{
Jemma L. Hawkins ${ }^{1,3}$, Kathryn J. Thirlaway ${ }^{1}$, Karianne Backx², \\ and Deborah A. Clayton ${ }^{1}$
}

ADDITIONAL INDEX WORDS. natural environment, exercise, attention restoration theory, community gardening

SUMMARY. This study explored the potential benefits of allotment gardening for healthy aging, focusing on the opportunities for outdoor physical activity, social support, and contact with nature that allotment gardening provides. Participants included 94 individuals aged between 50 and 88 years who were members of various indoor and outdoor activity groups. The participants completed physiological measures and psychometric scales of self-rated health, perceived stress, physical activity level, and perceived social support. A significant difference in perceived stress levels was observed between the activity groups. Allotment gardeners reported significantly less perceived stress than participants of indoor exercise classes $(P<0.05)$. As there were no significant differences in reported levels of social support and physical activity, explanations for the allotment gardeners' lower stress levels focus on the potential contribution of engagement with nature and psychological restoration. These findings represent a step toward understanding the benefits of allotment gardening activity as a health-promoting behavior in later life.

$\mathrm{T}$ here is a growing body of evidence that highlights the potential benefits of horticulture in later life (Collins and O'Callaghan, 2008), and as a favored leisure pursuit of older adults in the United Kingdom (Dunnett and Qasim, 2000), gardening may be a particularly beneficial form of physical activity for promoting healthy aging. Recent studies by Park et al. $(2008,2009)$ and Sommerfeld et al. (2010) have explored the physiological and psychological health of older

Preliminary findings of this research were presented at the UKPHA Annual Public Health Forum, 24th25th Mar. 2010

This research is a portion of a thesis to be submitted by the primary author for the fulfillment of a research degree.

This research was funded by the Academic Development Fund of the University of Wales Institute Cardiff.

The authors thank the members and organizers of Cardiff Walking for Health, Cardiff EXTEND, Cardiff Organic Gardeners, the Lisvane and Radyr Gardening Clubs, Llanishen Healthy Hearts Group, and Cardiff Allotments Secretaries. We would also like to thank the anonymous reviewers for their helpful comments and feedback.

The authors declare that they have no conflicts of interest with respect to authorship or publication of this article.

${ }^{1}$ Cardiff School of Health Sciences, University of Wales Institute Cardiff, Wales, CF5 2YB, United Kingdom

${ }^{2}$ Cardiff School of Sport, University of Wales Institute Cardiff, Wales, CF5 2YB, United Kingdom

${ }^{3}$ Corresponding author. E-mail: jhawkins@uwic.ac.uk. adult gardeners. Park et al. (2009) observed significantly higher physical function and significantly less bodily pain amongst individuals classified as active gardeners when compared with those classified as non-gardeners. Sommerfeld et al. (2010) showed significantly higher levels of physical activity, life satisfaction, and self-rated health in their sample of gardeners aged 50 years or older when compared with non-gardeners from the same age range. These findings are similar to previous studies that have shown gardening activity to be associated with improved grip strength, lower blood pressure, and enhanced psychological well-being (Reynolds, 1999, 2002). Research with residents of care institutions has also shown improvements in health and well-being as a result of cultivating house plants and time spent in gardens (Collins and O'Callaghan, 2008; Rappe and Kivelä, 2005)

More recently, van den Berg et al. (2010a) showed that allotment gardeners aged 62 years or older reported better scores on measures of health and well-being when compared with non-gardeners. Similar to the findings of Sommerfeld et al. (2010), the allotment gardeners also reported higher levels of physical activity when compared with the non-gardeners, but it is not made clear whether the nongardeners conducted other forms of physical activity and whether these were in any way similar to allotment gardening activity. In the United Kingdom, allotment gardens are legally defined in the Allotments Acts as "a piece of land not exceeding 40 poles in extent which is wholly or mainly cultivated by the plot-holder for the production of vegetables or fruit by him/herself and family" (Allotments Regeneration Initiative, 2007). An allotment site consists of a collection of allotment plots where plot-holders garden individually but in close proximity to one another.

Despite recent advancements in the understanding of the potential health and well-being benefits of gardening, there is a lack of knowledge about the specific components of the activity which may construe particular health benefits. The growing evidence base suggests that the benefits of gardening could be a result of the combination of outdoor physical activity with exposure to nature, and in some instances, the opportunity for social interaction (Sempik et al., 2005).

It is likely that the physical exercise obtained during gardening activity will have benefits to health. There is evidence to suggest that is the case for the lower intensity leisure time physical activity that gardening provides, as well as more vigorous intensity activity (Pretty et al., 2005). For example, moderate and low intensity physical activities such as cycling and walking have been linked to lower mortality rates when compared with sedentary lifestyles (Matthews et al., 2007) as well as reductions in systolic blood pressure, waist and hip circumferences, and improvements in functional capacity (Tully et al., 2007). Exercise intensity in such studies usually involves

\begin{tabular}{llll}
\hline $\begin{array}{l}\text { Units } \\
\begin{array}{l}\text { To convert U.S. to SI, } \\
\text { multiply by }\end{array}\end{array}$ & U.S. unit & SI unit & $\begin{array}{l}\text { To convert SI to U.S., } \\
\text { multiply by }\end{array}$ \\
\hline 0.3048 & $\mathrm{ft}$ & $\mathrm{m}$ & 3.2808 \\
2.54 & inch(es) & $\mathrm{cm}$ & 0.3937 \\
0.4536 & $\mathrm{lb}$ & $\mathrm{kg}$ & 2.2046 \\
0.1333 & $\mathrm{~mm}$ mercury & $\mathrm{kPa}$ & 7.5006
\end{tabular}


physical activities that have a metabolic energy expenditure equivalent (MET) level of less than 10, as categorized in the Ainsworth compendium of physical activities (Ainsworth et al., 2000 ). For example, brisk walking is coded as having a MET intensity level ranging from 3.8 to 5 , and gardening activities also fall within a similar MET level range. Research conducted with older adults has demonstrated that gardening can offer a level of caloric expenditure, which meets the recommended government guidelines for moderate intensity exercise (Park et al., 2008).

While physical activity can have direct health benefits as a result of physiological exertion and improved fitness, much research has also shown that it can lead to the improvement of psychosocial factors including stress levels (Starkweather, 2007). Researchers have argued that outdoor activities such as gardening may have stress-buffering properties as a result of the opportunity for contact with nature. Pretty (2004) describes three different levels of engagement with nature, which have been shown to have health benefits: viewing nature, being in the presence of nature, and active participation and involvement in nature. Gardening offers this third level of engagement as one is actively involved with nature while gardening and not merely in its presence. This active participation with nature is thought to have greater benefits than mere passive observation (Collins and O'Callaghan, 2008). Explanations for the potential synergistic benefit of exercising outdoors while engaging with nature have drawn upon "attention restoration theory" (Hartig et al., 2003; Kaplan, 1995 ) which posits that natural settings which confer a sense of "being away" from things have a beneficial restorative impact on cognitive resources such as attention and concentration, and can reduce fatigue. Cognitive restoration has been shown to be more likely to occur when exercising in natural environments than in urban environments (Bodin and Hartig, 2003). Ottosson and Grahn (2005) showed increased attentional performance in elderly care home residents following a period of outdoor leisure time compared with a period of indoor leisure time. Contact with nature and green space has also been linked to psychophysiological stress reduction (van den Berg et al., 2010b). It has been argued that green exercise may buffer against the effects of stress on physical and psychological health outcomes (van den Berg et al., 2007, 2010b).

A recent empirical study from the "Vitamin G" project in The Netherlands further explored the psychophysiological stress reduction benefits that gardening may construe (van den Berg and Custers, 2011). Salivary cortisol was measured before and after a stress-inducing task following which participants were allocated to an indoor reading activity or outdoor gardening activity. The researchers observed stronger stress recovery in participants of the gardening activity after controlling for baseline cortisol levels and time of day. Ineffective stress recovery is predictive of late life depression (Rappe and Kivelä, 2005) and is thought to be damaging to physical health through pathways such as chronic arousal of the sympathetic nervous system, immune suppression, and general allostatic load (Hartig et al., 2003).

Much of the research on the benefits of contact with nature has studied individual participants being exposed to natural scenes, views, or experiences. However, many activities in natural settings, such as gardening, also offer the opportunity for social contact (Sempik et al., 2005). Allotment gardening, in particular, offers contacts with the many other allotment plot-holders and thus can offer a social context to the activity when neighboring plot-holders are present. A large body of research highlights social contact as a key variable in healthy aging with findings linking social support to measures such as mortality and quality of life (Sugiyama and Ward Thompson, 2007). Glass et al. (1999) showed that overall survival was linked to activities that provided social contact and which were productive, even after controlling for health status and functional ability. Supportive social environments have been shown to promote the benefits of exercise (Bodin and Hartig, 2003), and this effect might occur through a stress reduction mechanism as social support is known to be a buffer against stress (Sugiyama and Ward Thompson, 2007).

As for outdoor physical activity, increased social interaction has been cited as a possible mediating factor in the associations between both physical activity and nature, with health outcomes serving an overall indirect effect of outdoor physical activity on health (Andrews, 2001). Participants of physical activity in natural settings often report that it provides opportunities for social interaction with likeminded people (Clayton, 2007), which may then lead to increased social contacts and support. In the case of allotment gardening in the United Kingdom, Milligan et al. (2004) examined older people's experiences of the cultivation of an allotment plot using diary and interview methods. Their analyses describe this type of gardening as stress busting, empowering, and enjoyable. The authors emphasized the benefits of the social interaction experienced, concluding that such communal gardening is more beneficial to physical and psychological health than traditional home gardening.

There is a lack of knowledge regarding specific benefits of gardening activity for older adults, with much of the existing findings relying on selfreported data and suboptimal objective measures of health (Windle et al., 2008). It is likely that the reported benefits to health and well-being of gardening are a result of a combination of outdoor physical activity, contact with nature, social interaction, and other potentially health-promoting factors-all of which are arguably in more abundance in the case of allotment gardening.

This cross-sectional study involved the measurement of health status and stress levels in older adult allotment gardeners and participants of other popular British leisure pursuits to compare the potential benefits. It was hypothesized that the groups would differ on physiological and self-reported health measures, as well as perceived stress levels, depending on whether they offered opportunities for being outdoors, increased social support, and contact with nature. In particular, it was hypothesized that the members of the activities that offered more of these opportunities would report lower stress levels and demonstrate better physiological and self-reported health. Furthermore, it was hypothesized that the allotment group would report the lowest stress levels and score most favorably on the health measures as a result of the combined effects of partaking in an outdoor physical activity that offers active participation 
with nature in the context of a social environment.

\section{Materials and methods}

SAMPLE AND ACTIVITY GROUPS. Adults aged over 50 years were recruited to the study from various local activity groups. The cutoff age was set at 50 years old as one of the groups was an "over 50 group," and it was intended that all members would be eligible to take part in the research. The study was advertised to group members using leaflets, posters, and visits from the researcher. Interested individuals then signed up for more information and were contacted subsequently to arrange the data collection. The activity groups that were contacted included walking groups, allotment sites, gardening groups, and indoor exercise groups from within the city of Cardiff, UK. The groups were defined as follows: 1) allotment gardeners carry out their gardening activity on an individual plot of land within a site consisting of many other gardening plots, 2) home gardeners only carry out gardening activity within their home garden, 3 ) members of local health walks obtain outdoor activity during walk routes that include a mixture of natural and rural environments, and 4) members of indoor exercise groups perform physical activity inside leisure centers or similar community venues.

These groups were selected for their variation in the provision of outdoor physical activity, social interaction, and varying levels of engagement with nature so that the potential contribution of these attributes to health status and stress levels could be compared. For example, gardening provides active engagement with nature (Pretty, 2004), whereas the walking groups were only occasionally in the presence of nature during their activity as the walk routes include a mixture of natural and urban environments. In addition, allotment gardeners (and the indoor exercise and walking groups) have more opportunities for social contact and interaction than home gardeners. The benefits of the activities as a whole were under investigation rather than the specific benefits of physical activity, so the activity groups were selected for offering similar levels of exercise intensity using standardized tables, in an attempt to ensure that physical activity level would not confound the results. All four activities have been shown to have a moderate intensity range of 3 to $6 \mathrm{METs}$ as detailed in the "physical activities compendium" (Ainsworth et al., 2000) as well as in research conducted specifically with older adults (Park et al., 2008; Stewart et al., 2001). At the point of recruitment, it was confirmed with each individual that the activity group which they were recruited from was their most frequent form of physical activity. Ethical approval was granted by the School of Health Sciences Ethical Committee at University of Wales Institute, Cardiff, UK, with all participants completing an informed consent form.

Procedure. The study involved two components; five physiological health measures, and a questionnaire containing several psychometric scales and some demographic questions. The health measures were conducted at the site of the activity group or at a convenient community venue and took no longer than $30 \mathrm{~min}$ to carry out. Participants were given the results of these measures as a thank you for taking part; however, no other incentive was offered for participation. After this appointment participants took home the questionnaire to complete and return in a freepost envelope.

Physiological measures. Body mass was measured using electronic weighing scales (model 880; SECA, Hamburg, Germany) to the nearest $0.1 \mathrm{~kg}$, participants were instructed to remove their shoes and any heavy items of clothing or accessories. Height was measured while the participants' shoes were removed, using an electronic height rod (Soehnle, Backnang, Germany). Instructions required participants to stand up straight with their chin parallel to the floor while their height was measured to the nearest centimeter. Body mass index (BMI) was then calculated using the equation [body mass (in kilograms) height ${ }^{2}$ (in meters)]; this measure is often used as an indicator of obesity, which is a modifiable risk factor for age-related diseases. BMI has been shown to be a valid predictive measure of cardiovascular mortality and morbidity (van Dis et al., 2009).

Systolic and diastolic blood pressures (in millimeters of mercury) were measured in a seated position using an electronic blood pressure monitor (705-CP; Omron, Kyoto, Japan). Participants were seated for $5 \mathrm{~min}$ before taking the measurements. The average of three consecutive recordings was calculated. This method was selected as increases in blood pressure are a known consequence of acute stress (Steptoe, 2008). In addition, decreases in blood pressure have been frequently observed as outcomes of physical activity interventions (e.g., Tully et al., 2007) including exercising while viewing natural scenes (Pretty et al., 2005).

Lung function was measured using a spirometer (LMMS03; Micro Medical Plus, Chatham, UK). The measure was conducted in an upright seated position. Participants were instructed to take a deep breath to fill their lungs and then to force the air out into the device by breathing out as fast as possible until all of the air is exhaled and the lungs are empty. The best of three consecutive recordings of the forced vital capacity (FVC) measure was used in the analysis. Respiratory function is considered an important component of physiological fitness, and improvements are often reported as outcomes of physical activity interventions (Starr et al., 2003). Decline in FVC has been shown to predict survival rates and has excellent test-retest reliability (Traynor et al., 2004).

Psychosocial measures. The questionnaire contained psychometric tools for the measurement of perceived social support and physical activity level to ascertain whether the groups differed on these dimensions. This was following the assumptions that the groups would have similar levels of physical activity but might differ on levels of perceived social support because of variations in the opportunities for social interaction within the activities. The questionnaire also included the outcome measures of perceived stress and self-reported health status. Scales were selected for having robust psychometric properties and being appropriate for use with older adults. Where possible, the shorter and more straightforward versions of the scales were used to keep the questionnaire to a manageable length. Details of the scales are provided in Table 1.

Demographics. An additional questionnaire included one-item questions to collect demographic information about age, gender, ethnicity, and marital-, employment-, and smokingstatus so that these potentially confounding variables could be controlled for within the analyses. Information 


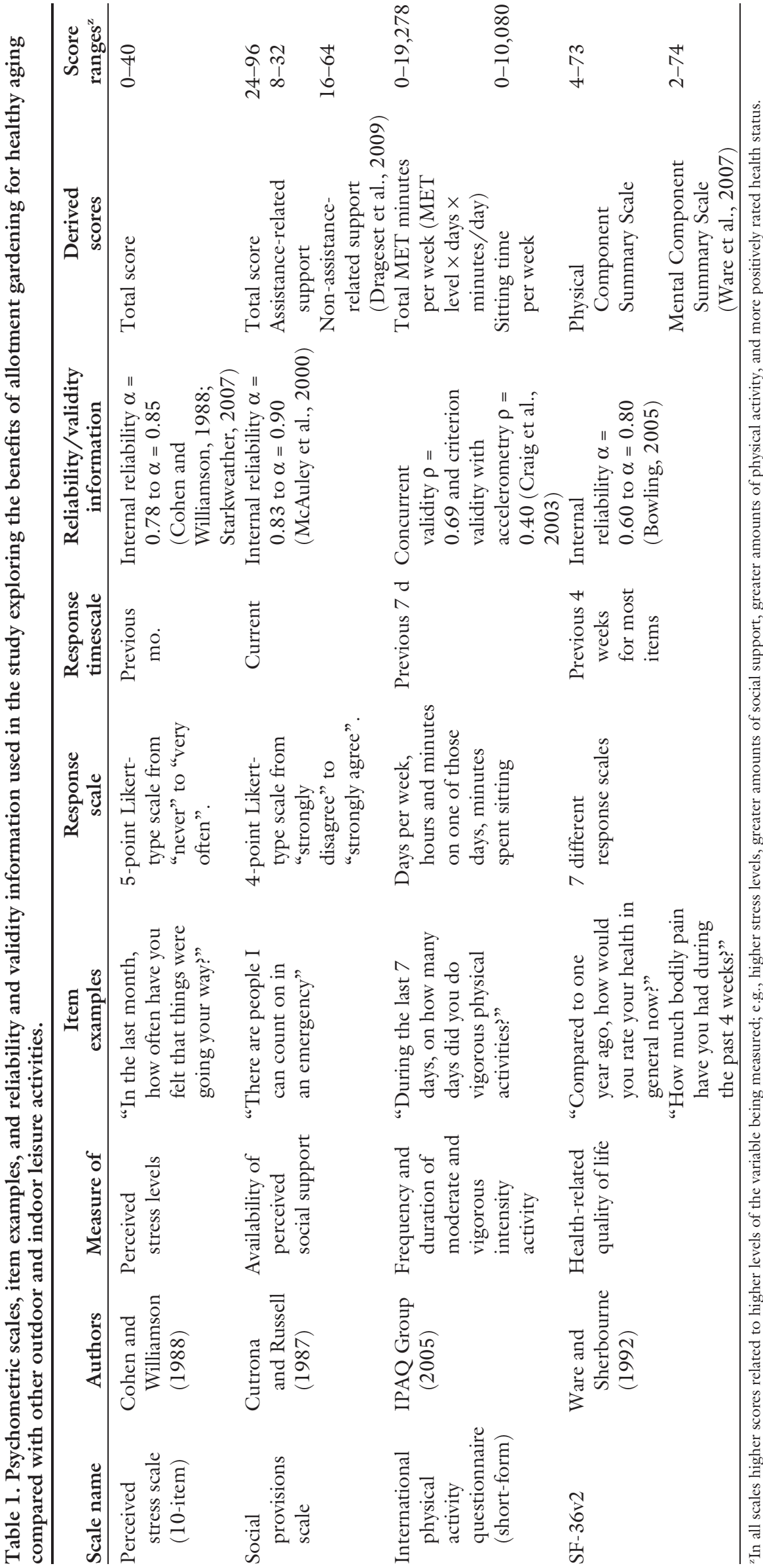

was also collected about whether participants suffered from any diagnosed illness or were taking any current medication. As a measure of socioeconomic status based on area deprivation, Townsend index scores (Townsend et al., 1988) were calculated for each participant based on their residential postcode. This index is based on census information about unemployment, car ownership, housing tenure, owner occupation, and overcrowded living conditions within a specified geographical unit. Within the standardized UK scores, zero represents the national average, scores above zero indicate higher levels of deprivation than the average, and scores below zero represent lower levels of deprivation. The scores are also categorized into quintiles, from 1 to 5 with $1=$ lowest deprivation, $3=$ average levels of deprivation, and $5=$ highest deprivation.

Data analysis. To account for age, height, and gender differences in the lung function data, FVC scores were transformed into percentages of the predicted value for each individual's age, gender, and height. Systemic pulse pressure was calculated as $\left(\mathrm{P}_{\text {systolic }}-\mathrm{P}_{\text {diastolic }}\right)$. An aging index (AI) was then created from the physiological data following a similar procedure to Tell and Nilsson (2006) using three out of the seven physiological measures: BMI, FVC, and pulse pressure. For each measure, the distribution of the scores was divided into quartiles and the least healthy quartile (the furthest from the most healthy values) for each measure was assigned a score of 1 . Participants in the other three quartiles were assigned a score of 0 . The score points for each participant were computed, creating an AI with possible scores ranging from 0 to 3 , with 0 representing healthy scores obtained on all three measures.

The psychometric scales [perceived stress scale (Cohen and Williamson, 1988), social provisions scale (Cutrona and Russell, 1987), IPAQ-S (IPAQ Group, 2005), SF-36v2 (Ware et al., 2007)] were all scored according to the authors' specifications. For the SF36 component scores (Physical Component Summary Scale and Mental Component Summary Scale) and IPAQ total MET minutes per week, median values and interquartile ranges are reported. For the rest of the psychometric 
tools, mean values and standard deviations are reported. This is following the recommendations of the scale developers in all instances. For the categorical demographic variables, total number of participants that fall into each category is reported as well as the percentage of the overall sample that this represents.

Data analysis was performed using SPSS for windows (version 17.0; IBM, Armonk, NY). One-way analysis of variance (ANOVA), KruskalWallis, chi-square, and Fisher's exact tests were conducted to determine any significant differences in sociodemographic characteristics between the groups. One-way ANOVAs were used to determine any differences between the groups in the psychosocial and health measures. Results are presented as $95 \%$ confidence intervals.

\section{Results}

The overall response rate for completion of the questionnaire was $87.8 \%$, in total 94 participants took part in the study. The mean age of the participants $( \pm S D)$ was $67 \pm 8.5$ years with ages ranging from 50 to 88 years. All participants were of white ethnicity.

Sociodemographic characteristics of the sample are shown in Table 2 . The groups were fairly homogenous, apart from a significant difference in the proportion of males and females in each group and significant variation in socioeconomic status as measured using the Townsend index.

Of the psychosocial variables measured (perceived stress, perceived social support, physical activity levels, and health-related quality of life), the only significant difference that existed among the four activity groups was for perceived stress level $(\mathrm{F}=4.925$, $P<0.05)$ as illustrated in Table 3 . Bonferroni posthoc tests revealed that the difference in perceived stress levels between the indoor exercise group and the allotment gardeners group was significant $(P<0.05)$ but that those among the other groups were not. While the allotment gardeners had the highest mean scores of social support, self-rated physical health and physical activity levels, and the lowest mean sitting time, these were not significantly higher than the means of the other activity groups.

Regarding the heterogeneity of the four activity groups, there was a significantly higher proportion of men in the allotment gardeners group than any of the other activity groups, and there was also a significant difference in the variance of socioeconomic status between groups. These differences may have been involved in the lower stress levels observed in the allotment gardeners.

The possibility that the difference in stress level was due to an effect of socioeconomic status was tested using analysis of covariance, entering the continuous Townsend score as a covariate. While the main effect of activity group on perceived stress was still found $(\mathrm{F}=$ $4.947, P<0.05)$, there was no main effect of socioeconomic status, as indexed by the Townsend score $(\mathrm{F}=$ $0.630, P>0.05)$. There were also no significant interactions between the two variables. However, there were interesting trends in the data as displayed in Fig. 1, which displays the Townsend score as a median split. There is an observed difference in perceived stress scores between allotment gardeners from high and low deprived areas, as indexed by the Townsend score median split. Allotment gardeners from higher deprivation areas reported lower stress levels than those from lower deprivation areas. Figure 1 shows that this difference is not observed for the other activity groups.

Because of the low numbers of males and females in some of the groups, it was not possible to test for the effect of gender on the difference in stress levels between the groups using parametric statistics. It was possible to compare stress levels between males and females, collapsed across the four activity groups using a MannWhitney $U$ test. There was no significant difference in the perceived stress levels of males and females overall ( $U=$ 783.5, $Z=-0.956, P>0.05)$.

While there were differences in the levels of reported stress as hypothesized, there were no significant differences observed among the health statuses of the groups, as indexed by the SF36 summary scores, the individual

Table 2. Demographic characteristics of the four activity groups in the study exploring the benefits of allotment gardening for healthy aging compared with other outdoor and indoor leisure activities.

\begin{tabular}{|c|c|c|c|c|c|}
\hline & $\begin{array}{l}\text { Indoor } \\
\text { exercisers } \\
(n=23)\end{array}$ & $\begin{array}{l}\text { Walkers } \\
(n=25)\end{array}$ & $\begin{array}{c}\text { Allotment } \\
\text { gardeners } \\
(n=25)\end{array}$ & $\begin{array}{c}\text { Home } \\
\text { gardeners } \\
(n=21)\end{array}$ & $P$ \\
\hline \multicolumn{6}{|c|}{ mean $\pm S D$} \\
\hline Age (years) & $72.9 \pm 6.9$ & $62.4 \pm 6.8$ & $65.7 \pm 9.1$ & $69.5 \pm 7.7$ & $0.000^{*}$ \\
\hline \multicolumn{6}{|c|}{ no. (\%) } \\
\hline Gender & & & & & $0.000^{*}$ \\
\hline Male & $3(13)$ & $8(32)$ & $17(68)$ & $2(9.5)$ & \\
\hline Female & $20(87)$ & $17(68)$ & $8(32)$ & $19(90.5)$ & \\
\hline Ethnicity & & & & & 1.000 \\
\hline White & $23(100)$ & $25(100)$ & $25(100)$ & $21(100)$ & \\
\hline Marital status & & & & & 0.074 \\
\hline Single & $3(13)$ & $2(8)$ & $2(8)$ & $2(10)$ & \\
\hline With partner & $10(43.5)$ & $18(72)$ & $20(80)$ & $10(50)$ & \\
\hline Divorced/separated & $1(4.3)$ & $2(8)$ & $1(4)$ & $0(0)$ & \\
\hline Widowed & $9(39.1)$ & $3(12)$ & $2(8)$ & $8(40)$ & \\
\hline Employment status: & & & & & 0.909 \\
\hline Retired & $20(87)$ & $20(80)$ & $20(80)$ & $17(81)$ & \\
\hline Part-time employed & $3(13)$ & $5(20)$ & $3(12)$ & $4(19)$ & \\
\hline Townsend quintile & & & & & $0.001^{*}$ \\
\hline 1 & $15(65.2)$ & $10(40)$ & $13(52)$ & $19(90.4)$ & \\
\hline 2 & $0(0)$ & $0(0)$ & $2(8)$ & $1(4.8)$ & \\
\hline 3 & $5(21.8)$ & $5(20)$ & $6(24)$ & $1(4.8)$ & \\
\hline 4 & $3(13)$ & $2(8)$ & $3(12)$ & $0(0)$ & \\
\hline 5 & $0(0)$ & $8(32)$ & $1(4)$ & $0(0)$ & \\
\hline \multicolumn{6}{|l|}{ Health } \\
\hline Smoker & $1(4.3)$ & $0(0)$ & $1(4)$ & $0(0)$ & 0.857 \\
\hline Diagnosed illness & $13(56.5)$ & $13(52)$ & $15(60)$ & $15(71.4)$ & 0.695 \\
\hline Prescribed medication & $19(86.4)$ & $15(60)$ & $19(76)$ & $15(71.4)$ & 0.321 \\
\hline
\end{tabular}

${ }^{2}$ Townsend quintiles range from 1 (lowest deprivation) through 3 (average deprivation) to 5 (highest deprivation). * Significant at $P<0.05$. 
Table 3. Average scores and results of tests of difference on the psychosocial measures between the four activity groups in the study exploring the benefits of allotment gardening for healthy aging compared with other outdoor and indoor leisure activities.

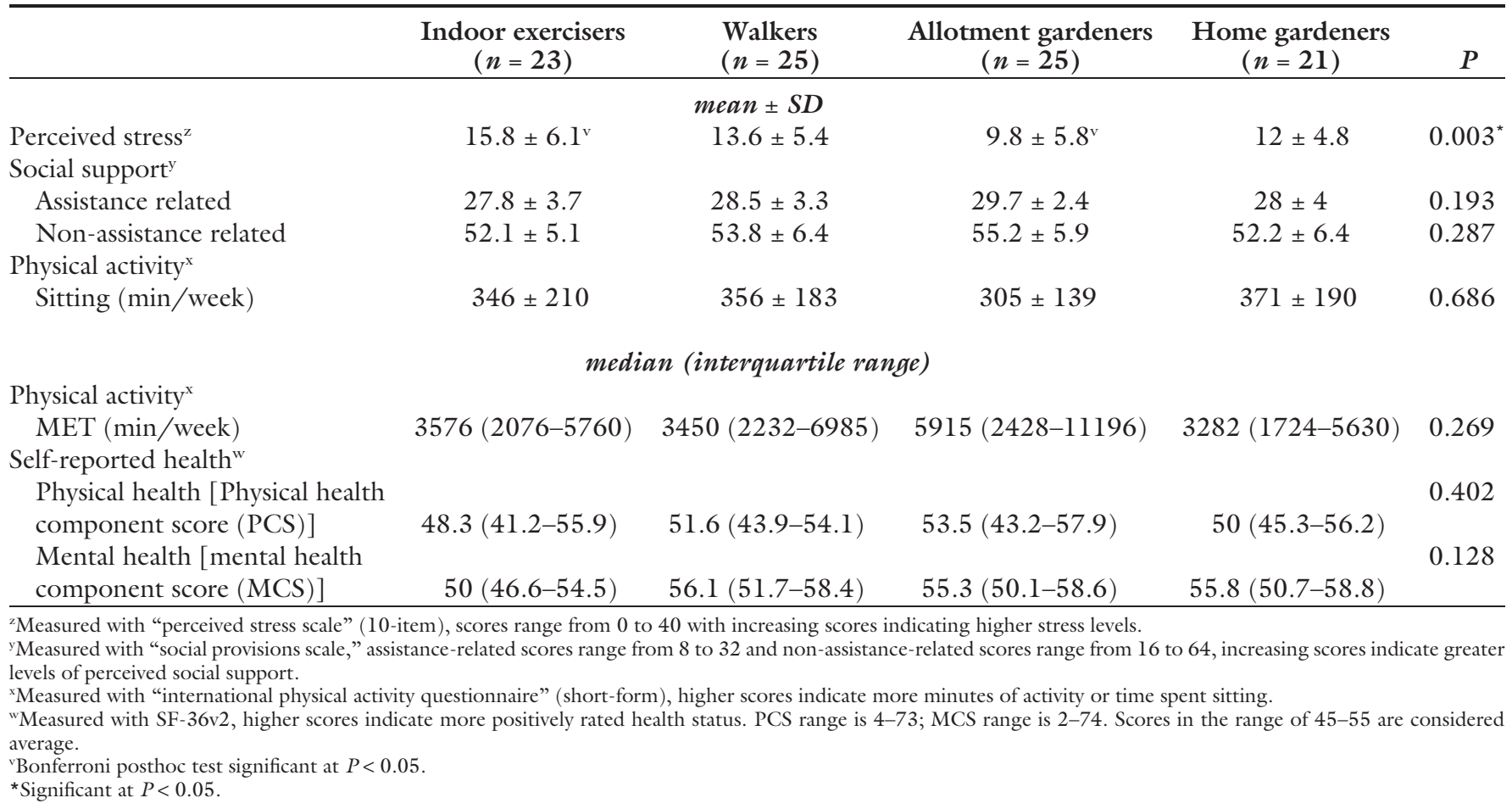

physiological measures and the calculated AI, see Table 4. It is worth noting from this data that although nonsignificant, the allotment group obtained more favorable scores in some of the physiological measures (BMI, lung function, and self-reported physical health) than participants of the other activity groups.

\section{Discussion}

Consistent with the hypothesis, allotment gardeners aged over 50 years reported lower levels of perceived stress than participants of other outdoor and indoor activity groups although these differences were only statistically significant between the indoor exercise group and the allotment gardeners group. Controlling for the effects of gender and socioeconomic status did not alter the results. However, it should be noted that stress levels tended to be lower for allotment gardeners from higher deprivation areas.

It was hypothesized that the combination of exercising outdoors with the opportunity for active engagement with nature and increased social contact would mean that allotment gardeners reported the lowest stress levels of the four activity groups, based on previous research (Milligan et al., 2004). However, the social support measure

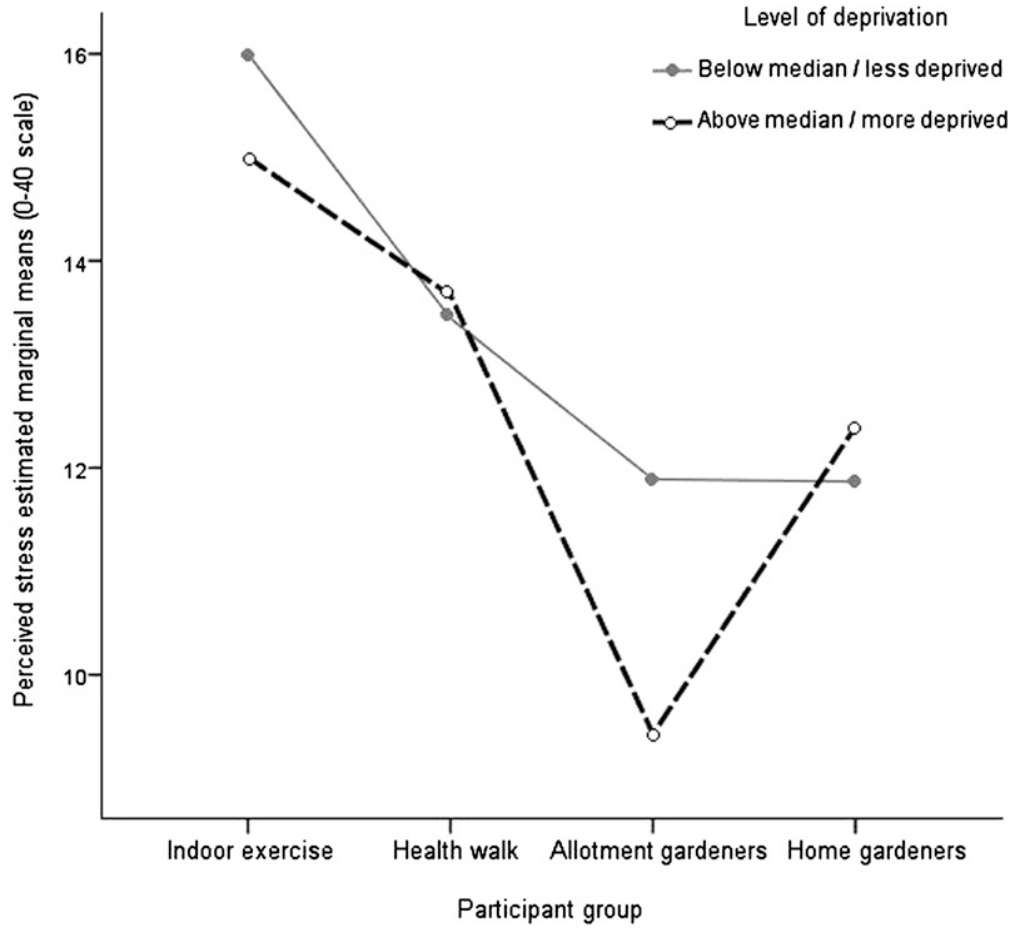

Fig. 1. Relationship between activity group and level of deprivation as indexed by the Townsend score (displayed as a median split) for mean perceived stress scores, measured using the 10-item "perceived stress scale". Data from the study exploring the benefits of allotment gardening for healthy aging compared with other outdoor and indoor leisure activities.

did not reveal a significant difference between levels of perceived support among the four activity groups, suggesting that this may not be the reason for the lower levels of stress in the allotment group. It was hypothesized that the opportunity for social interaction within an activity 
Table 4. Average scores and results of tests of difference on the physiological measures between the four activity groups in the study exploring the benefits of allotment gardening for healthy aging compared with other outdoor and indoor leisure activities.

\begin{tabular}{lccccc}
\hline & $\begin{array}{c}\text { Indoor } \\
\text { exercisers } \\
(\boldsymbol{n}=\mathbf{2 3})\end{array}$ & $\begin{array}{c}\text { Walkers } \\
(\boldsymbol{n}=\mathbf{2 5})\end{array}$ & $\begin{array}{c}\text { Allotment } \\
\text { gardeners } \\
(\boldsymbol{n}=\mathbf{2 5})\end{array}$ & $\begin{array}{c}\text { Home } \\
\text { gardeners } \\
(\boldsymbol{n}=\mathbf{2 1})\end{array}$ & $\boldsymbol{P}$ \\
\hline & \multicolumn{3}{c}{ mean $\pm S D$} \\
${\text { Body mass index }(\mathrm{BMI})^{\mathrm{z}}}$ & $26.2 \pm 5.2$ & $26.9 \pm 4.3$ & $25.5 \pm 3.3$ & $27.3 \pm 2.2$ & 0.441 \\
Pulse pressure & $64.3 \pm 15.4$ & $54.6 \pm 14.2$ & $62.4 \pm 16.3$ & $63.7 \pm 15.1$ & 0.104 \\
Lung function $(\%)^{\mathrm{x}}$ & $94.8 \pm 25.4$ & $99.4 \pm 34.2$ & $104.9 \pm 33.3$ & $93.6 \pm 21.9$ & 0.567
\end{tabular}

Aging index scorew

$\begin{array}{lcccc}0 & 7(30.4) & 3(12) & 12(48) & 3(14.3) \\ 1 & 10(43.5) & 15(60) & 9(36) & 13(61.9) \\ 2 & 6(26.1) & 5(20) & 3(12) & 5(23.8) \\ 3 & 0 & 2(8) & 1(4) & 0\end{array}$

${ }^{2}$ Calculated as [body mass (in kilograms) $\div$ height ${ }^{2}$ (in meters)], a BMI between 18.5 and 25 is considered healthy; $1 \mathrm{~kg}=2.2064 \mathrm{lb}, \mathrm{l} \mathrm{m}=3.2808 \mathrm{ft}$.

${ }^{y}$ Calculated as $\left(\mathrm{P}_{\text {systolic }}-\mathrm{P}_{\text {diastolic }}\right)$, lower values are considered more healthy.

xercentage of predicted forced vital capacity lung function value based on age/height/gender, higher scores are considered more healthy.

"Calculated using the method described by Tell and Nilsson (2006), 0 indicates healthy values scored on all three physiological variables.

would be associated with lower stress levels because there is much evidence to suggest a causal link between the two variables (Sugiyama and Ward Thompson, 2007). In this study, perception of social support availability was measured following the idea that it is the perception of available support that is important for stress reduction (Cohen and Wills, 1985). However, the opportunity for social interaction during a group activity may not always result in increases in the perception of available support. Furthermore, although the home gardeners conduct their gardening activity without a regular opportunity for increased social interaction, they may have other opportunities for this within their lives, for example, gardening clubs. This possibility may explain why there was no significant difference among the groups on perceived levels of social support. A measure that gauges social support specific to an activity may have generated more useful data.

While the allotment gardeners group reported the highest mean physical activity levels, this was not significantly different from the means of the other activity groups because of high variance. Thus, it cannot be concluded that the difference in stress levels was due to greater amounts of physical activity in the allotment gardening group. The four activity types were selected as they have been shown to offer similar levels of exercise intensity, as indexed by MET levels; however, it may be that certain activities lend themselves to more regular participation as reflected in the trends of the reported physical activity levels. The indoor exercise and walking groups took place at scheduled times and venues; however, there were several of these available each week to allow for regular participation if a person so wished. With allotment and home gardening, the time spent partaking in the activity is not specifically scheduled, so regular participation depends on the individual's initiative. It could be argued that either of these arrangements allows for more frequent participation, but a tentative explanation of the higher (yet not significant) physical activity level of the allotment gardeners might be that an allotment plot tends to require more regular attendance than an average home garden to look after.

Concerning contact with nature, it was assumed that the indoor exercise groups have the least engagement with nature during their activity (even if they had window views of nature) and that the gardening groups have the most engagement with nature during their activity as gardening work involves active participation with nature, as described by Pretty (2004). Attention restoration theory [ART (Kaplan, 1995)] provides an explanation as to why engagement with nature may lead to stress reduction. The theory purports that the restoration of cognitive capacities such as attention and concentration occurs as a result of a feeling of being away from routine mental contents, in combination with attention being effortlessly driven by interest and sustained in a coherent environment, the demands of which do not exceed the inclinations of being there. Kaplan and Kaplan (1989) argue that natural environments meet these requirements to a high extent and more than other environments. This cognitive restoration has been associated with stress reduction in empirical studies (van den Berg et al., 2007) and it has been suggested that activity in restorative environments can interrupt the negative stress process (Hartig et al., 2003).

Lower stress levels were observed in the allotment gardeners that live in more deprived areas. This might be explained by a greater benefit in getting away from the home environment-if the home environment is in a deprived area. Mitchell and Popham (2008) observed reduced health inequalities in terms of mortality caused by circulatory disease in populations living in areas that had greater access to greenspace. They draw upon the previously mentioned findings that link greenspace to health through a stress reduction pathway to explain this. It is thought that populations from less affluent areas may be more likely to experience health benefits as a result of physical activity in natural environments than in other settings. This, in part, may offer some explanation of the observed lower stress levels in the high deprivation allotment gardeners.

Greenspaces, including gardens, have often been linked to ideas of escape and private retreats within research on well-being (Dunnett and Qasim, 2000; Guite et al., 2006). There was an observed difference between the reported stress levels of allotment gardeners and home gardeners in this study although this difference was not statistically significant. If natural green spaces provide opportunity for psychological restoration and stress reduction because they offer time away from the hassles of daily life, it can be argued that one is more likely to experience a feeling of being away from things when they are physically away from their everyday surroundings, which may not occur when gardening at home. Results from a survey of garden center 
visitors have shown that many people with gardens view them as an extension of the home (Clayton, 2007), which may not allow for escape and time away from a stressful home life. However, this is merely speculation, and there is research evidence, which suggests that escape is an important element of the home garden as well (Bhatti and Church, 2000). Indeed, it seems that gardens attached to residences and institutions are of particular importance to clinical populations where retreat to the garden is the main escape from the indoors for these individuals (Rappe and Kivelä, 2005; Sempik et al., 2005).

There are several limitations to this study that must be noted. First, it is a cross-sectional study, so a cause and effect relationship between allotment gardening and stress levels cannot be determined. It may be that people who have allotments have more time to commit to this lifestyle, which could be an element of a low stress life. Second, the stress levels reported were relatively low on the $0-40$ scale in all four activity groups, despite the differences observed. As highlighted in the results section, there were trends in the data that did not reach statistical significance but were in line with the hypothesis that allotment gardeners would score more favorably on the physiological measures. These trends suggest that further larger scale studies investigating the physical health benefits of allotment gardening are warranted.

In addition, while MET levels have previously been shown to be similar for the four activities involved in the study, a measure of physical fitness may have been useful in ascertaining whether a difference in fitness levels exists among individuals who take part in the four activities studied. This measure was not included in the present study as there were concerns about limiting the amount of time and effort required by the participants to complete the measures included. Self-report measures of stress and other psychosocial variables were adopted as we were particularly interested in measuring individual perceptions. Future studies could add to the evidence base by using more objective measures where available.

The results reported here are intriguing in terms of health promotion in later life. While outdoor activities have been considered in terms of stress reduction and health before, there has been little research that compares a variety of different activities for these properties. As there were no differences between the activity groups on measures of social support and physical activity level, other components of allotment gardening have been considered as possible causes of the lower stress levels in this group. It could be that the various components of the activity interact to benefit psychological well-being, or that there are meditational processes at work; for example, it has been suggested that social support may mediate the effects of physical activity on health (Andrews, 2001) and this may be the case for any effects on stress levels as well. Because of the conservative sample size here, mediational analyses were not possible, thus future research is needed to further the understanding of potential mechanisms involved in the observed differences in stress levels.

To expand on the results found here, prospective longitudinal work will be useful in terms of identifying cause and effect. Comparisons within different gardening activities are also required to establish evidence of the specific components that confer any benefits, such as allotment plot size and site location. Studies using nongardeners could help to determine whether a keen interest or experience of gardening is required to benefit from participation. Measures of duration of gardening activity, as well as perceptions of engagement with nature and environmental aesthetics would be useful to collect in future research to inform the idea that gardening provides a deeper engagement with nature than other outdoor activities. This is something that is planned for the authors' subsequent research.

Specific practice implications of these findings are limited as further evidence is required to enhance understanding of the components of gardening that construe any health benefits in later life. However, the growing evidence base suggests that gardening could represent an effective healthpromoting outdoor activity for later life, which advocates the empowerment of older adults to include gardening activity in their leisure pursuits. In addition, further understanding of the benefits of gardening for healthy aging will be of use to the horticultural industry for the promotion of gardening activity.

\section{Literature cited}

Ainsworth, B.E., W.L. Haskell, M.C. Whitt, M.L. Irwin, A.M. Swartz, S.J. Strath, W.L. O'Brien, D.R. Bassett, Jr., K.H. Schmitz, P.O. Emplanincourt, D.R. Jacobs, Jr., and A.S. Leon. 2000. Compendium of physical activities: An update of activity codes and MET intensities. Med. Sci. Sports Exerc. 32:S498-S516.

Allotments Regeneration Initiative. 2007. Allotments: A Plotholder's Guide. 6 July 2011. <http://www.farmgarden.org.uk/ ari/documents/plotholdersguide.pdf $>$.

Andrews, G.R. 2001. Care of older people: Promoting health and function in an aging population. BMJ 322:728-729.

Bhatti, M. and A. Church. 2000. 'I never promised you a rose garden': Gender, leisure and home-making. Leisure Studies 19:183-197.

Bodin, M. and T. Hartig. 2003. Does the outdoor environment matter for psychological restoration gained through running? Psychol. Sport Exerc. 4:141-153.

Bowling, A. 2005. Measuring health: A review of quality of life measurement scales. 3rd ed. Open University Press, Maindenhead, UK.

Clayton, S. 2007. Domesticated nature: Motivations for gardening and perceptions of environmental impact. J. Environ. Psychol. 27:215-224.

Cohen, S. and G.M. Williamson. 1988. Perceived stress in a probability sample of the United States, p. 31-67. In: S. Spaceman and S. Oskamp (eds.). The social psychology of health. Sage Publications, Newbury Park, CA.

Cohen, S. and T.A. Wills. 1985. Stress, social support, and the buffering hypothesis. Psychol. Bull. 98:310-357.

Collins, C.C. and A.M. O'Callaghan. 2008. The impact of horticultural responsibility on health indicators and quality of life in assisted living. HortTechnology 18:611-618.

Craig, C.L., A.L. Marshall, M. Sjöström, A.E. Bauman, M.L. Booth, B.E. Ainsworth, M. Pratt, U. Ekelund, A. Yngve, J.F. Sallis, and P. Oja. 2003. International physical activity questionnaire: 12-country reliability and validity. Med. Sci. Sports Exerc. 35:1381-1395.

Cutrona, C.E. and D.W. Russell. 1987. The provisions of social relationships and adaptation to stress, p. 37-67. In: W.H. Jones and D. Perlman (eds.). Advances in personal relationships. JAI Press, Greenwich, CT.

Drageset, J., E.G. Eide, H.A. Nygaard, M. Bondevik, M.W. Nortvedt, and G.K. Natvig. 2009. The impact of social support 
and sense of coherence on health-related quality of life among nursing home residents: A questionnaire survey in Bergen, Norway. Intl. J. Nurs. Stud. 46:66-76.

Dunnett, N. and M. Qasim. 2000. Perceived benefits to human well-being of urban gardens. HortTechnology 10:40-45.

Glass, T.A., C. Mendes De Leon, R.A. Marotolli, and L.F. Berkman. 1999. Population based study of social and productive activities as predictors of survival among elderly Americans. BMJ 319:478-483

Guite, H.F., C. Clark, and G. Ackrill. 2006. The impact of the physical and urban environment on mental wellbeing. Public Health 120:1117-1126.

Hartig, T., G.W. Evans, L.D. Jamner, S.D. Davis, and T. Garling. 2003. Tracking restoration in natural and urban field settings. J. Environ. Psychol. 23:109-123.

IPAQ Group. 2005. Guidelines for Data Processing and Analysis of the International Physical Activity Questionnaire (IPAQ). 17 July 2011. <http://www.ipaq. ki.se/scoring.pdf>.

Kaplan, R. and S. Kaplan. 1989. The experience of nature: A psychological perspective. Cambridge University Press, Cambridge, UK.

Kaplan, S. 1995. The restorative benefits of nature: Toward an integrative framework. J. Environ. Psychol. 15:169-182.

Matthews, C.E., A.L. Jurj, X.O. Shu, H.L. Li, G. Yang, Q. Li, Y.T. Gao, and W. Zheng. 2007. Influence of exercise, walking, cycling, and overall nonexercise physical activity on mortality in Chinese women. Amer. J. Epidemiol. 165:1343-1350.

McAuley, E., S. Blissmer, D.X. Marquez, G.J. Jerome, A.F. Kramer and J. Katula. 2000. Social relations, physical activity, and well-being in older adults. Preventive Medicine 31:608-617.

Milligan, C., A. Gatrell, and A. Bingley. 2004. 'Cultivating health': Therapeutic landscapes and older people in northern England. Soc. Sci. Med. 58:1781-1793.

Mitchell, R. and F. Popham. 2008. Effect of exposure to natural environments on health inequalities: An observational population study. Lancet 372:1655-1660.

Ottosson, J. and P. Grahn. 2005. Comparison of leisure time spent in a garden with leisure time spent indoors: On measures of restoration in residents in geriatric care. Landscape Res. 30:23-55.

Park, S.A., C.A. Shoemaker, and M.D. Haub. 2008. A preliminary investigation on exercise intensities of gardening tasks in older adults. Percept. Mot. Skills 107: 974-980.
Park, S.A., C.A. Shoemaker, and M.D. Haub. 2009. Physical and psychological health conditions of older adults classified as gardeners or non-gardeners. HortScience 44:206-210.

Pretty, J. 2004. How nature contributes to mental and physical health. Spirituality Health Intl. 5:66-78.

Pretty, J., J. Peacock, M. Sellens, and M. Griffin. 2005. The mental and physical health outcomes of green exercise. Intl. J. Environ. Health Res. 15:319-337.

Rappe, E. and S.-L. Kivelä. 2005. Effects of garden visits on long-term care residents as related to depression. HortTechnology 15:298-303.

Reynolds, V. 1999. The green gym: An evaluation of a pilot project in Sonning Common, Oxfordshire. Oxford Brookes University, Oxford, UK.

Reynolds, V. 2002. Well-being comes naturally: An evaluation of BTCV Green Gym at Portslade, East Sussex. Oxford Brookes University, Oxford, UK.

Sempik, J., J. Aldridge, and S. Becker. 2005. Health, well-being and social inclusion. Therapeutic horticulture in the UK. Policy Press, Bristol, UK.

Sommerfeld, A.J., T.M. Waliczek, and J.M. Zajicek. 2010. Growing minds: Evaluating the effect of gardening on quality of life and physical activity level of older adults. HortTechnology 20:705-710.

Starkweather, A.R. 2007. The effects of exercise on perceived stress and IL-6 levels among older adults. Biol. Res. Nurs. 8: 186-194.

Starr, J.M., I.J. Deary, and S. Macintyre. 2003. Associations with successful ageing in the "healthy old people in Edinburgh" cohort: Being well, fit and healthy. Aging Clin. Exp. Res. 15:336-342.

Steptoe, A. 2008. Psychophysiological stress reactivity and hypertension. Hypertension 52:220-221.

Stewart, A.L., C.J. Verboncoeur, B.Y McLellan, D.E. Gillis, S. Rush, K.M. Mills, A.C. King, P. Ritter, and B.W. Brown. 2001. Physical activity outcomes of CHAMPS II: A physical activity promotion program for older adults. J. Gerontol. A Biol. Sci. Med. Sci. 56:M465-M470.

Sugiyama, T. and C. Ward Thompson. 2007. Outdoor environments, activity and the well-being of older people: Conceptualising environmental support. Environ. Plan. A 39:1943-1960.

Tell, D. and P.M. Nilsson. 2006. Early aging in middle-aged men is associated with adverse social factors and increased mortality risk: The Malmo preventive project. Scand. J. Public Health 34:346-352.

Townsend, P., P. Phillimore, and A. Beattie. 1988. Health and deprivation: Inequalities and the north. Croom Helm, London.

Traynor, B.J., H. Zhang, J.N. Shefner, D. Schoenfeld, and M.E. Cudkowicz. 2004. Functional outcome measures as clinical trial endpoints in ALS. Neurology 63:1933-1935.

Tully, M.A., M.E. Cupples, N.D. Hart, J. McEneny, K.J. McGlade, W.S. Chan, and I.S. Young. 2007. Randomised controlled trial of home-based walking programmes at and below current recommended levels of exercise in sedentary adults. J. Epidemiol. Community Health 61:778-783.

van den Berg, A.E. and M.H.G. Custers. 2011. Gardening promotes neuroendocrine and affective restoration from stress. J. Health Psychol. 16:3-11.

van den Berg, A.E., T. Hartig, and H. Staats. 2007. Preference for nature in urbanized societies: Stress, restoration, and the pursuit of sustainability. J. Soc. Issues 63:79-96.

van den Berg, A.E., J. Maas, R.A. Verheij, and P.P. Groenewegen. 2010b. Green space as a buffer between stressful life events and health. Soc. Sci. Med. 70:1203-1210.

van den Berg, A.E., M. van WinsumWestra, S. de Vries, and S.M.E. van Dillen. 2010a. Allotment gardening and health: A comparative study among allotment gardeners and their neighbors without an allotment. Environ. Health 9:74.

van Dis, I., D. Kromhout, J.M. Geleijnse, J.M. Boer, and W.M. Verschuren. 2009. Body mass index and waist circumference predict both 10-year nonfatal and fatal cardiovascular disease risk: Study conducted in 20,000 Dutch men and women aged 20-65 years. Eur. J. Cardiovasc. Prev. Rehabil. 16:729-734.

Ware, J.E. and C.E. Sherbourne. 1992. The Mos 36-item short-form health survey (Sf-36). I. Conceptual-framework and item selection. Med. Care 30:473-483.

Ware, J.E., M. Kosinski, J.B. Bjorner, D.M. Turner-Bowker, B. Gadnek, and M.E. Maruish. 2007. User manual for the SF-36v2 ${ }^{\circledR}$ health survey. 2nd ed. QualityMetric, Lincoln, RI.

Windle, G., D. Hughes, P. Linck, I. Russell, R. Morgan, B. Woods, V. Burholt, R. Tudor Edwards, C. Reeves, and S. Tien Yeo. 2008. Public health interventions to promote mental well-being in people aged 65 and over: Systematic review of effectiveness and cost-effectiveness. Inst. Medical Social Care Res., Univ. of Wales, Bangor, UK. 